Pediat. Res. 6: 675-681 (1972)

Brain

fetal development

liver

lung

palmitate-1 $-{ }^{14} \mathrm{C}$ phospholipids

placenta

sterols

triglycerides

\title{
In Vitro Metabolism of Palmitic Acid in Human Fetal Tissue
}

\author{
Tamotsu Yoshioka and Jacques F. Roux ${ }^{[41]}$
}

Department of Reproductive Biology, Case Western Reserve University School of Medicine and the Perinatal Clinical Research Center at Cleveland Metropolitan General Hospital, Cleveland, Ohio, USA

\section{Extract}

In vitro uptake of palmitic acid-1 $1{ }^{14} \mathrm{C}(\mathrm{PA})$ by human fetal tissue at various periods of development and its conversion to lipids and $\mathrm{CO}_{2}$ has been studied. Incorporation of PA into placental phospholipids, triglycerides, and free fatty acids (FFA) was proportional to time of incubation (5-120 min) and to concentration of FFA in the medium (1.0 to $3.0 \mathrm{~mm}$ ). Production of ${ }^{14} \mathrm{CO}_{2}$ was independent of the studied concentrations of FFA in the medium, but it increased linearly with incubation time. Brain, lung, and liver readily metabolize PA to ${ }^{14} \mathrm{C}$-lipids and ${ }^{14} \mathrm{CO}_{2}$. In anaerobiosis, ${ }^{14} \mathrm{CO}_{2}$ production was decreased fourfold and triglyceride synthesis twofold, but phospholipid synthesis was unchanged. Incubation at $0^{\circ}$ decreased placental ${ }^{14} \mathrm{C}$ lipid synthesis and ${ }^{14} \mathrm{CO}_{2}$ production to near zero. However, incorporation of PA into placental tissue FFA was unchanged. The uptake of PA by young placenta (12-16 weeks) into triglycerides was $50 \%$ higher than that by term placenta. When placental tissue, preincubated with $\mathrm{PA}$, was reincubated without FFA, ${ }^{14} \mathrm{C}$-lipid synthesis and ${ }^{14} \mathrm{CO}_{2}$ production continued as readily as when FFA were present in the medium. The radioactivity of placental FFA decreased threefold, however, at the end of $2 \mathrm{hr}$. Most of the decrease in tissue $\mathrm{C}^{14}-\mathrm{FFA}$ can be accounted for in the medium and in the other tissue lipids. The data suggest that FFA of maternal and/or fetal origin can be the source of fetal lipids and energy. The placental transfer of FFA is a non-energy dependent process.

\section{Speculation}

The data suggest that the lipid metabolism of the human fetus could depend, in part, on the availability of FFA originating from maternal or fetal circulation. Since the regulation of plasma FFA is altered in disorders of carbohydrate metabolism, the diabetic or prediabetic state of pregnancy might influence the lipid metabolism of the developing fetus.

\section{Introduction}

Injection of labeled palmitic acid parenterally to the pregnant woman results in the appearance of radioactive FFA in the fetal compartment [25]. The human placenta, perfused in vitro, transfers palmitate from the maternal to the fetal side [23]. These data indicate that, as in sheep [26], guinea pig [7, 10], rabbit [25], rat $[4,6,11]$, and rhesus monkey $[15]$, maternal fatty acids cross the human placenta. There is, therefore, a strong possibility that circulating fetal fatty acids, whether of maternal origin or synthesized by fetal tissue, can be the precursors of fetal lipids. To test this hypothesis, it 
was decided to incubate in the presence of PA slices of human placenta, fetal brain, liver, and lung obtained from fetuses of early and term gestation.

The uptake of PA into tissue lipids and its conversion to carbon dioxide was taken as an index of the potential capability of fetal tissue to metabolize fatty acids during development. The data show that each fetal tissue studied metabolized PA to triglyceride, sterol, sterol ester, phospholipid, and carbon dioxide. These findings are in agreement with data obtained in adult rat tissue in vitro and suggest that fetal FFA are utilized to some extent for energy production and to a large extent for the synthesis of lipids as in adult rat tissue $[3,9,16,20]$.

\section{Methods}

\section{Tissue and Incubation Techniques}

Brain, lung, liver, and placenta of human fetuses were obtained by therapeutic abortion between the 12th and 16th weeks of gestation. (The investigators did not participate in the decision to interrupt pregnancy.) Term placentas were obtained at the time of normal delivery. Gestational age of fetal development was determined by crown-rump measurement [13].

Placentas and fetal tissues were immediately placed in ice. After dissection, each organ or tissue was cut in small pieces and washed and rinsed in ice cold isotonic saline until the washed product was clear. Thin slices (300-600 mg) were made for in vitro incubation [19]. The slices were incubated for various periods of time in an atmosphere of $95 \% \mathrm{O}_{2}-5 \% \mathrm{CO}_{2}$. During aerobic incubation, the concentration of oxygen in the flask was never less than 70\%; during anaerobic incubation, the mean concentration of oxygen was $3.0 \pm$ $0.3 \%$ (SE) as determined by the Astrup technique [1].

In each incubated vessel were $4 \mathrm{ml}$ Krebs-Ringer phosphate buffer containing $3 \%$ bovine serum albumin fraction $V$ [29] and 1.0-3.0 millimoles FFA extract mixed with ${ }^{14} \mathrm{C}$-palmitic acid and 10 millimoles glucose [16]. The FFA extract was prepared by saponification of human adipose tissue [16]. The amount of PA was adjusted in each experiment so that the specific activity of the medium FFA was $15 \mu \mathrm{Ci} /$ millimole FFA. Palmitic acid-1-14 C [30] was purified by thin-layer chromatography (TLC) and then shown to be $98 \%$ pure by gas liquid chromatography (GLC). The $\mathrm{pH}$ of medium was 7.4 at time of incubation and the temperature was kept at $37.0^{\circ}$ in a Dubnoff incubator shaker.

In some experiments, placental tissue was incubated at $0^{\circ}$. In the centerwell of each flask were placed filter paper strips and $0.2 \mathrm{ml} 1.25 \mathrm{~N} \mathrm{NaOH}\left(\mathrm{CO}_{2}\right.$-free) for the collection of respiratory $\mathrm{CO}_{2}$ [28]. In four experiments, release of tissue FFA from placental slices was studied. Placental tissue was incubated with palmitate- $1{ }^{14} \mathrm{C}$ for $1 \mathrm{hr}$ at $37.0^{\circ}$; the slices were then removed, rinsed in isotonic saline, and transferred to a similar incubation medium without added FFA. The second incubation at $37.0^{\circ}$ lasted $5,30,60$, or 120 min.

\section{Techniques of Extraction and Measurement}

At the end of incubation, each tissue was transferred to cold isotonic saline and washed several times to remove the FFA [16]. Total lipids were then extracted [5]. Each lipid sample was plated on precoated silica gel plates [31] for TLC separation with hexane-diethylether-glacial acetic acid $(90: 10: 1)$ [22]. The plates were sprayed with $2^{\prime}, 7^{\prime}$-dichlorofluorescein and the lipids were visualized under ultra-violet light. The areas corresponding to phospholipids, triglycerides, sterols, sterol esters, and FFA were identified by comparison with known standards run simultaneously. Two milligrams of a standard lipid mixture [32] containing phospholipids and cholesterol were added as carrier to each sample before TLC.

The lipids were scraped off the plate with a razor blade, collected on glassine paper, and transferred to scintillation vials containing a mixture of Cab-o-sil in 2,5-bis-2,5-test butylbenzoxazol (BBOT) and toluene [33]. Radioactivity was determined in a liquid scintillation system [34]. The maximum counting error was $6 \%$.

Quenching, due to the added fluorescein, was corrected by adding ${ }^{14} \mathrm{C}$-toluene to a blank area scraped from each plate. In 30 experiments, the quenching was $15.5 \pm 1.0 \%$. This percentage was not significantly different from that observed with an internal standard in four experiments. Recovery of palmitic acid-1-14 $\mathrm{C}$ added to non-incubated placental tissue and carried through the entire extraction and plating procedure was $79.3 \pm 2.5 \%(\mathrm{n}=4)$.

FFA concentrations in the medium and slices were determined [24]. The production of respiratory ${ }^{14} \mathrm{CO}_{2}$ was measured after the ${ }^{14} \mathrm{CO}_{2}$ was precipitated and counted as ${ }^{14} \mathrm{C}$-barium carbonate [27].

After incubation, GLC was used to determine the fatty acid composition and radioactivity of the various placental lipid fractions [17]. Nine-tenths of each lipid fraction was separated by a stream splitter and collected in a fraction collector [35] containing quartz wool-filled tricarb cartridges [33]. Each tube was immersed in scintillation counting solution $(12 \mathrm{~g} \mathrm{BBOT}$ and $2500 \mathrm{ml}$ 
toluene) and counted in a liquid scintillation counter. The recovery of labeled fatty acids of various chain lengths by this technique was $60 \pm 5 \%$ (sD) of the injected quantities. Glucose concentration of the incubation medium was measured by the glucose-oxidase technique [36].

\section{Results}

Disappearance of FFA from the Medium, Placental FFA Content, and Radioactivity of Lipids in the Medium before and after Incubation with Palmitate ${ }^{14} C$

Added FFA disappeared during the first $30 \mathrm{~min}$ of incubation $(0.25 \mu$ moles/gram wet weight). Longer incubation periods were characterized by continuous utilization of medium FFA in some experiments and by an increase in medium FFA in others. However, the observed changes were at the limit of sensitivity of our technique. It was concluded, therefore, that tissue FFA concentration equilibrates in $30 \mathrm{~min}$ with the FFA added to the medium. The concentration of FFA in placental tissue before and after incubation was found to remain constant (mean, 3.5 $\pm 0.8 \mu$ moles/gram wet weight). Radioactivity of phospholipids, triglycerides, sterols, and sterol esters, extracted from the incubation medium after incubation, was less than $2 \%$ of total radioactivity of the free fatty acid fractions of the medium. After $2 \mathrm{hr}$ of incubation, $30 \%$ of the added glucose was utilized by the placental slices.

Incorporation of Palmitic Acid-1-14C into Tissue Lipids

Placental Tissue. The incorporation of PA into placental tissue lipids is tabulated in Table I. When tissues were incubated at $37^{\circ}$, the increase in $\mathrm{FFA}$ in the medium from 1.0 to $3.0 \mu$ moles led to an increase in incorporation of palmitate-1-14 $\mathrm{C}$ into phospholipids, triglycerides, sterol esters, and FFA. This increase continued in a linear manner up to $6 \mu \mathrm{moles} / \mathrm{ml}$.

When the temperature of the incubation system remained at $0^{\circ}$, the same trend was observed in the incorporation of PA into phospholipids, triglycerides, and sterol esters in the medium. This incorporation was reduced at each concentration studied-1/10 for phospholipids, $1 / 100$ for triglycerides, and $1 / 3$ to $1 / 8$ for sterol esters. The uptake of FFA into the tissue, however, was not different from that observed at $37^{\circ}$.

When slices from term placentas were incubated in the presence of 2.2 millimoles FFA, the radioactivities of phospholipids, triglycerides, sterols and sterol esters increased linearly over a period of $2 \mathrm{hr}$. The concentration of labeled FFA in the placenta remained unchanged however (Fig. 1). When placentas of 12-16 wks of gestation were incubated under similar conditions, incorporation of PA into triglycerides of the 12$16 \mathrm{wk}$ placentas was twice that of term placentas $(P<$ 0.01) (Fig. 2).

When placental tissue of any gestational age was incubated in nitrogen, the radioactivity measured in each lipid fraction was not statistically different from that found in similar tissue incubated in $95 \% \mathrm{O}_{2}-5 \%$ $\mathrm{CO}_{2}$, except for triglyceride synthesis which was decreased $49 \%(P<0.04)$ (Table I).

When placental slices were preincubated with PA and transferred to a medium without FFA but containing added glucose, the radioactivity in tissue FFA found after $2 \mathrm{hr}$ of incubation decreased $50 \%$ below the preincubation level. Radioactivity of the other

Table $I$. Effect of temperature and of nitrogen atmosphere on palmitic acid incorporation into placental lipids and carbon dioxide ${ }^{1}$

\begin{tabular}{lccccccc}
\hline Incubation system & $\begin{array}{c}\text { Free fatty acids } \\
\text { in medium, mM }\end{array}$ & Phospholipids & Sterols & Free fatty acids & Triglycerides & Sterol esters & Respiratory $\mathrm{CO}_{2}$ \\
\hline Aerobic at $37^{\circ}$ for 1 & 1.0 & $1983 \pm 67$ & n.m. & $5632 \pm 933$ & $2269 \pm 1000$ & $79 \pm 8$ & $338 \pm 77$ \\
hr & 2.0 & $3342 \pm 216$ & n.m. & $25441 \pm 7873$ & $6989 \pm 427$ & $76 \pm 3$ & $530 \pm 84$ \\
& 3.0 & $5149 \pm 34$ & n.m. & $63768 \pm 11148$ & $9478 \pm 2361$ & $112 \pm 14$ & $502 \pm 145$ \\
\hline Aerobic at $0^{\circ}$ for $1 \mathrm{hr}$ & 1.0 & $113 \pm 30$ & n.m. & $6899 \pm 984$ & $31 \pm 9$ & $9 \pm 2$ & $11 \pm 2$ \\
& 2.0 & $329 \pm 57$ & n.m. & $30722 \pm 1721$ & $65 \pm 6$ & $21 \pm 1$ \\
& 3.0 & $686 \pm 63$ & n.m. & $66851 \pm 6322$ & $69 \pm 2$ & $34 \pm 3$ \\
\hline
\end{tabular}

1 See text for description of incubation. Values are expressed as dpm/gram wet weight and represent mean $\pm \mathrm{sE}$ of 3 experiments. 2 n.m.: not measured. 
Table II. Palmitic acid-1 ${ }^{14} \mathrm{C}$ incorporation into placental tissue lipids and conversion to respiratory $\mathrm{CO}_{2}{ }^{1}$

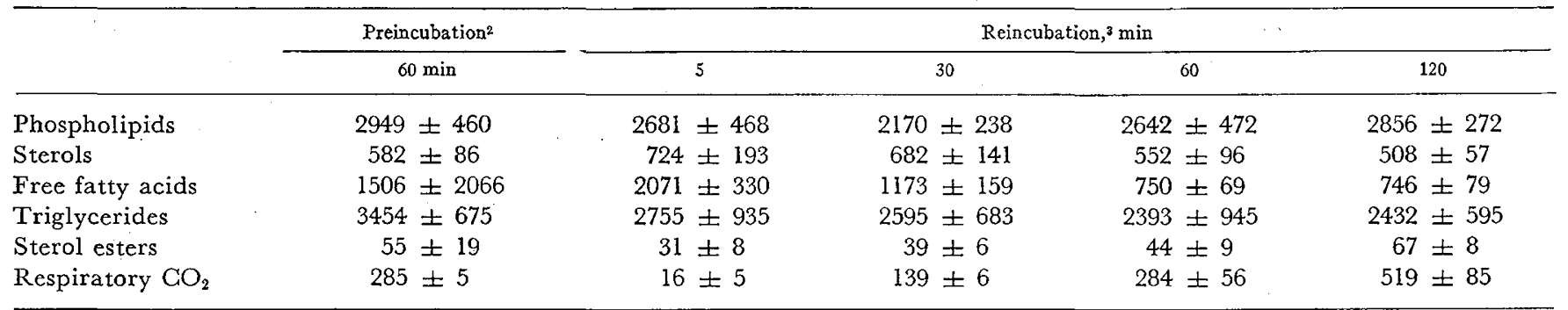

${ }_{1}^{1}$ Results are expressed as dpm/gram wet weight and represent mean $\pm \mathrm{sE}$ of 6 experiments.

${ }^{2}$ All tissues were incubated in $95 \% \mathrm{O}_{2}-5 \% \mathrm{CO}_{2}$ for $1 \mathrm{hr}$ in 2.2 millimoles palmitic acid-1 ${ }^{14} \mathrm{C}$ (specific activity, $15 \mu \mathrm{Ci} / \mathrm{millimole}$ ).

${ }^{3}$ Medium contained no free fatty acids but added glucose ( 10 millimoles). Incubation was at $37.0^{\circ}$ in $95 \% \mathrm{O}_{2}-5 \% \mathrm{CO}_{2}$.

lipid fractions did not change significantly when compared with the preincubation level, but there was a transitory decrease in ${ }^{14} \mathrm{CO}_{2}$ production at $5 \mathrm{~min}$ (Table II). FFA radioactivity which disappeared from placental slices could all be accounted for in the medium and in the radioactivity of the ${ }^{14} \mathrm{C}$-lipids.

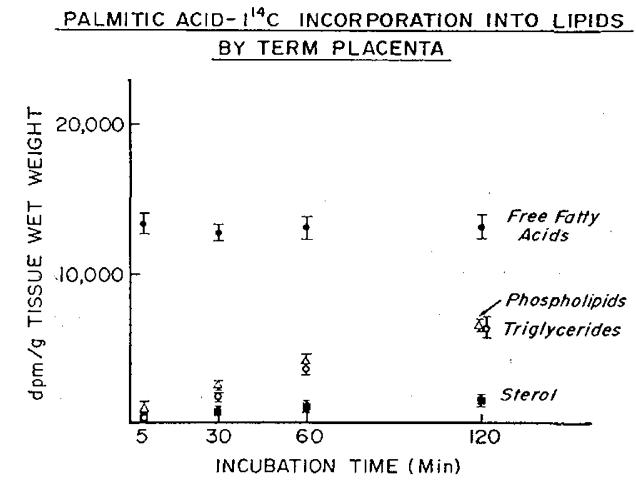

Fig. 1. Incorporation of palmitic acid-1 ${ }^{14} \mathrm{C}$ into lipids by term placenta. Results represent the average $\pm \mathrm{SE}$ of 14 experiments carried out in duplicate. Tissues were incubated in $95 \% \mathrm{O}_{2}-5 \mathrm{CO}_{2}$ in the presence of 2.2 millimoles free fatty acids and 10 millimoles glucose.

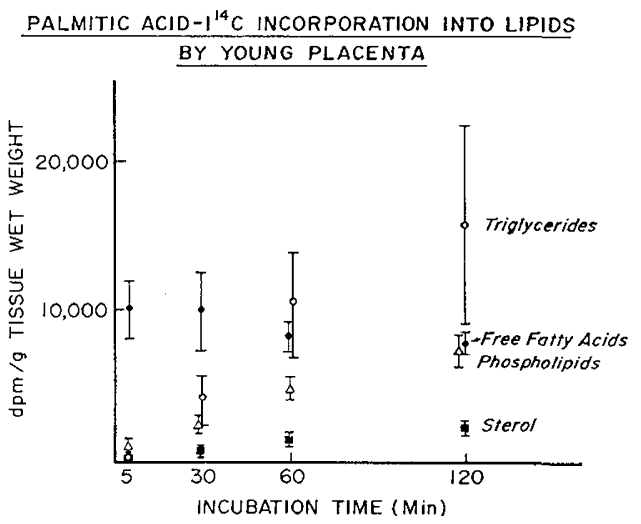

Fig. 2. Incorporation of palmitic acid-1 ${ }^{14} \mathrm{C}$ into lipids by young placenta. Results represent the average $\pm S E$ of 5 experiments carried out in duplicate. For conditions of incubation, see Fig. $I$.
Table III. Palmitic acid- $\mathrm{I}-{ }^{14} \mathrm{C}$ incorporation in to tissue lipids and conversion to respiratory $\mathrm{CO}_{2}$ by human fetal tissue ${ }^{1}$

\begin{tabular}{lccc}
\hline & Brain & Lung & Liver \\
\hline Phospholipids & $4111 \pm 1421$ & $3720 \pm 598$ & $6050 \pm 931$ \\
Sterols & $704 \pm 458$ & $940 \pm 518$ & $1245 \pm 641$ \\
Free fatty & $7578 \pm 1232$ & $7646 \pm 1450$ & $4407 \pm 1314$ \\
$\quad$ & & & \\
$\quad$ Tcids & & & \\
Triglycerides & $5503 \pm 1803$ & $2656 \pm 388$ & $8897 \pm 2129$ \\
Sterol esters & $37 \pm 15$ & $86 \pm 23$ & $754 \pm 172$ \\
Respiratory & $316 \pm 174$ & $505 \pm 205$ & $1062 \pm 199$ \\
$\quad \mathrm{CO}_{2}$ & & & \\
\hline
\end{tabular}

${ }^{1}$ Tissue was incubated at $37.0^{\circ}$ in $95 \% \mathrm{O}_{2}-5 \% \mathrm{CO}_{2}$ for $1 \mathrm{hr}$ in 2.2 millimoles ${ }^{1-14} \mathrm{C}$ palmitic acid (specific activity, $15 \mu \mathrm{Ci}$ / millimole) and 10 millimoles glucose (see text). Results are expressed as dpm/gram wet weight and represent mean $\pm \mathrm{SE}$ of 5 experiments.

Fetal Tissues. In Table III are presented the results of PA incorporation into the tissue of five 12- to 13-weekold fetuses. Brain, lung, and liver incorporated PA into the various lipid fractions. Although liver incorporated less ${ }^{14} \mathrm{C}$-palmitate into the FFA fraction than the other tissues $(P<0.05)$, incorporation into each lipid fraction was significantly higher by liver than by any other tissue $(P<0.05)$.

Conversion of Palmitic Acid-1-14C to Respiratory $\mathrm{CO}_{2}$. Different concentrations of FFA in the medium do not significantly stimulate the conversion by placental slices of $\mathrm{PA}$ to ${ }^{14} \mathrm{CO}_{2}$. At $0^{\circ}$, production of ${ }^{14} \mathrm{CO}_{2}$ was about $5 \%$ that of the control (Table I). However, production of respiratory ${ }^{14} \mathrm{CO}_{2}$ increased with the duration of incubation (Fig. 3). After $2 \mathrm{hr},{ }^{14} \mathrm{CO}_{2}$ production by $12-$ to 16 -wk placentas was $58 \%$ greater than that by term placentas. When tissue was incubated in an atmosphere of nitrogen, production of ${ }^{14} \mathrm{CO}_{2}$ from PA was decreased to $13 \%$ of the control (Table I).

When placental slices were preincubated aerobically and then reincubated in a medium free of FFA but containing glucose, production of ${ }^{14} \mathrm{CO}_{2}$ was almost 
entirely curtailed after $5 \mathrm{~min}$; it then increased to the preincubated level after $60 \mathrm{~min}$ and doubled at $2 \mathrm{hr}$ (Table II). Incubation of ${ }^{14} \mathrm{C}$-palmitate with fetal brain, lung, and liver produced a significant amount of respiratory ${ }^{14} \mathrm{CO}_{2}$ from PA (Table III). The net metabolism of $\mathrm{PA}$ to respiratory $\mathrm{CO}_{2}$ was most active in liver; lung was approximately half as active, while brain was approximately one-third as active.

Fatty Acid Composition of the Tissue Lipids. Determination of radioactivity in the fatty acids isolated from phospholipids, triglycerides, sterols, and sterol esters after separation by GLC indicates that $90 \%$ of the labeling was in the palmitic acid fraction of each lipid fraction. Fatty acids of longer or shorter chain lengths had insignificant amounts of radioactivity.

\section{Discussion}

The data show that human fetal tissues from the second and third trimester of pregnancy metabolize palmitic acid to lipid and respiratory carbon dioxide in vitro. These metabolic processes do not differ from those observed in adult rat tissue in vitro $[3,9,16,20]$. For many years glucose was considered to be the major source of fetal energy [6]. This view has been challenged by studies which show that the lamb fetus metabolizes glucose, amino acids, and fatty acids in vivo [8]. Therefore, our data suggest that fetal FFA may be a source of energy and of lipids to the fetus.

In these in vitro experiments, PA entered placental tissue slices very rapidly. This transfer from medium to tissue is apparently not an energy-dependent process or a limited diffusion process because the radioactivity of tissue FFA was the same whether the placental slice was incubated aerobically at $37^{\circ}$ or at $0^{\circ}$ or in an atmosphere of nitrogen. Under the latter conditions, however, ${ }^{14} \mathrm{CO}_{2}$ production was markedly curtailed. As evidence of the continuous exchange of FFA between tissue and medium, radioactivity of placental FFA decreased when the placenta was reincubated in a medium free of FFA. The loss of FFA radioactivity after one and two hours can be accounted for entirely in medium $\mathrm{FFA},{ }^{14} \mathrm{CO}_{2}$ production, and ${ }^{14} \mathrm{C}$-lipid synthesis. This indicates that ${ }^{14} \mathrm{C}$-fatty acids are metabolized and freed into the medium from the placenta.

The concentration of FFA in the incubation medium controls lipid synthesis in placental slices. As the concentration of FFA is increased, the incorporation of palmitic acid into placental lipids is stimulated. Although the study was conducted at one FFA concentration, fetal lung, liver, and brain seem to follow the same pattern of lipid metabolism. These data are simi-

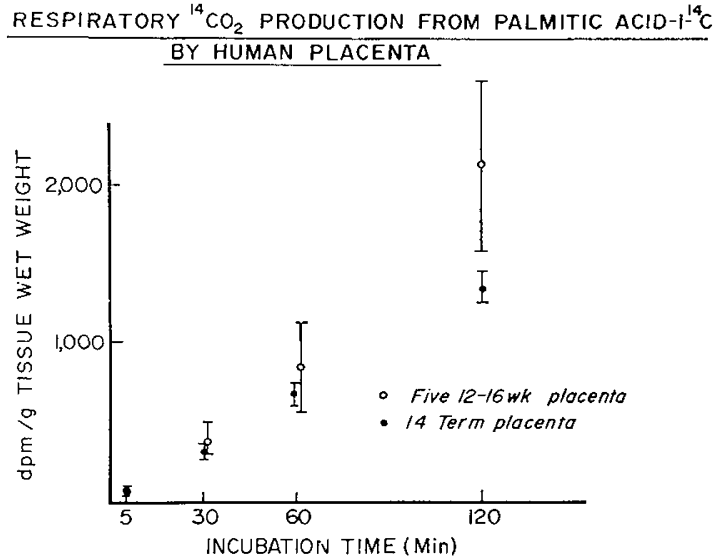

Fig. 3. Production of respiratory ${ }^{14} \mathrm{C}$ from palmitic acid-1 $1{ }^{14} \mathrm{C}$ by human placenta. Results represent the average $\pm \mathrm{SE}$ of 5 early and 14 term placentas. For conditions of incubation, see Fig. 1 .

lar to those found for adult rat liver, adipose tissue, lung, and diaphragm in which an increase in medium FFA concentration enhanced lipid synthesis $[2,3,9$, $16,20]$. It is therefore probable that lipid synthesis in the human fetus is also regulated by tissue FFA availability.

In every fetal tissue studied, except brain, conversion of palmitic acid to lipids was very similar. In fetal brain, the uptake was greater. This might be related to the rapid growth of brain in the early part of gestation.

Placental lipid metabolism changes with increasing gestation. The 12- to 16 -wk placenta converted more $\mathrm{PA}$ to ${ }^{14} \mathrm{CO}_{2}$ and ${ }^{14} \mathrm{C}$-triglycerides than did the term placenta. Since radioactivity of the FFA extracted from young placenta tended to decrease during incubation and was significantly lower after two hours than radioactivity of FFA from term placenta, young placenta metabolized FFA into triglycerides more rapidly than did term placenta. This observation is consistent with the increased glycogen content, glucose-6phosphatase activity, and oxygen consumption which have been demonstrated in young placenta, as compared with term placenta [27].

Degradation of fatty acids to carbon dioxide and their conversion to sterol takes place in fetal brain, lung, liver, and placenta. In placenta, carbon dioxide production was not stimulated by an increase in FFA concentrations in the incubation medium although the radioactivity of each millimole of FFA remained the same. This has been observed in adult tissue $[9,16]$. Since all fetal tissues studied catabolize fatty acids to ${ }^{14} \mathrm{CO}_{2}$, the oxidative mitochondrial enzyme system is present. Furthermore, conversion of fatty acids to 
${ }^{14} \mathrm{CO}_{2}$ is dependent on the availability of acyl-CoA synthetase, and the presence of carnitine palmityl transferase. Since these enzymes are present in human placental tissue [18], the other fetal tissues tested may have similar enzyme systems.

In an atmosphere of nitrogen, incorporation of PA into placental triglycerides and $\mathrm{CO}_{2}$ was markedly reduced from that which took place in oxygen; but incorporation into phospholipids was reduced to a much smaller extent. Explanations for the former may be that less triglycerides are synthesized because of a lack of ATP or that they are hydrolyzed in excess of their synthesis. The negligible effect of anoxia on phospholipid synthesis is more difficult to explain. The de novo synthesis of phosphatidic acid from glycerol-3phosphate and the availability of acylated fatty acids whose synthesis and production are only slightly curtailed by anoxia could account for this result. During incubation under nitrogen, dihydroxyacetone, glyceraldehyde-3-phosphate, glycerol-3-phosphate, and reduced pyridine nucleotides are still produced [12]. Therefore, phospholipid synthesis can proceed and the availability of reduced pyridine nucleotides may permit fatty acid acylation to continue. Another alternative is that the degradation of phospholipids is reduced in nitrogen.

The yield of ${ }^{14} \mathrm{CO}_{2}$ from ${ }^{14} \mathrm{C}$-palmitate in lung and brain incubations was less than that in the other tissues studied. This may be the result of a more rapid incorporation of ${ }^{14} \mathrm{C}$-palmitate into lipids than oxidation to ${ }^{14} \mathrm{CO}_{2}$. This may be a reasonable assumption because brain lipids have a slow turnover rate and lung tissue synthesizes phospholipids in increasing amounts until the end of gestation [21]. Another possibility is that palmityl-CoA-synthetase has less activity in brain and lung tissue than in liver and placenta. This has been demonstrated in the adult rat [14].

\section{Summary}

At various periods of gestation, the conversion of sodium palmitate- $1-{ }^{14} \mathrm{C}$ to lipids and respiratory ${ }^{14} \mathrm{CO}_{2}$ was measured in slices of human fetal brain, lung, liver, and placenta. The uptake of sodium palmitate${ }^{1-14} \mathrm{C}$ into placental slices is not an energy-dependent or a limited diffusion process, as was shown by incubations conducted in an atmosphere of nitrogen and at $0^{\circ}$. All fetal tissues studied converted sodium palmitate- $1-{ }^{14} \mathrm{C}$ to ${ }^{14} \mathrm{C}$-lipids (phospholipids, triglycerides, sterols, and sterol esters) and to ${ }^{14} \mathrm{CO}_{2}$. The reaction was linear and substrate-dependent over the range of concentrations studied up to $2 \mathrm{hr}$. The 12- to 16-wk placenta converted more sodium palmitate-1-14 $\mathrm{C}$ to triglycerides and ${ }^{14} \mathrm{CO}_{2}$ than the term placenta. Lung and brain tissues metabolized less sodium palmitate-1${ }^{14} \mathrm{C}$ to ${ }^{14} \mathrm{CO}_{2}$ than did liver or placenta. In nitrogen, ${ }^{14} \mathrm{C}$-triglyceride synthesis was curtailed more than ${ }^{14} \mathrm{C}$ phospholipid synthesis while production of respiratory ${ }^{14} \mathrm{CO}_{2}$ from PA was reduced. These observations correlate with those made in adult rat tissue. They indicate that human fetal tissues metabolize palmitic acid from an early stage of gestation and use it for energy production, at least in vitro.

\section{References and Notes}

1. Astrup, P., Jorgenson, K., Siggard-Anderson, O., and Engel, K.: The acid-base metabolism: a new approach. Lancet, $i$ : 1035 (1960).

2. Bailey, P. R., Cahill, G. F., Leboeuf, B., and Renold, E.: Studies of rat adipose tissue in vitro. V. Effect of glucose and insulin on the metabolism of palmitate-1.14 C. J. Biol. Chem., 235: 333 (1960).

3. Daviasova, M., Hahn, P., Drahota, Z., and Dominas, H.: The metabolism of ${ }^{14} \mathrm{C}$-palmitate in the lungs and liver of rats during their development. Biol. Neonat., 10:200 (1966).

4. FAIN, J. N., AND Scow, R. O.: Fatty acid synthesis in vivo in maternal and fetal tissues in the rat. Amer. J. Physiol., 210: 19 (1966).

5. Folch, J., Lees, M., And Sloane-Stanley, G. H.: A simple method for the isolation and purification of total lipids from animal tissues. J. Biol. Chem., 226: 497 (1957).

6. Goldwater, W. H., ANd Stetren, D., JR.: Studies in fetal metabolism. J. Biol. Chem., 169: 723 (1949).

7. Hershfield, M. S., ANd Nemeth, A. M.: Placental transport of free palmitic and linoleic acid in the guinea pig. J. Lipid Res., 9: 460 (1968).

8. James, E. J., Raye, J. R., Gresham, E. L., Makowski, E. L., Meschia, G., ANd Battaglia, F. C.: The normal oxygen consumption and respiratory quotient of the mammalian fetus (Abstract). Pediat. Res., 5: 419 (1971).

9. JEDEIKIN, L. A., AND WEINHOUSE, S.: Studies of the incorporation of palmitate- $1{ }^{14} \mathrm{C}$ into tissue lipids in vitro. Arch. BioChim. Biophys., 50: 134 (1954).

10. Kayden, H. J., Dancis, J., and Money, W. L.: Transfer of lipids across the guinea pig placenta. Amer. J. Obst. Gynec., 104: 564 (1969).

11. Koren, Z., AND SHAFRIR, E.: Placental transfer of free fatty acids in the pregnant rat. Proc. Soc. Exp. Biol. Med., 116: 411 (1964).

12. Lennarz, W. J.: Lipid metabolism. Ann. Rev. Biochem., 39: 359 (1970).

13. Patren, B. M.: Human Embryology, Ed. 2, p. 184. (McGraw Hill, New York, 1954).

14. Paude, S. V., ANd Mead, J. F.: Distribution of long chain fatty acid-activating enzymes in rat tissues. Biochim. Biophys. Acta, 152: 636 (1968).

15. Portman, O. W., Behrman, R. E., And Soltys, P.: Transfer of fatty acids across the primate placenta. Amer. J. Physiol., 216: 143 (1969). 
16. Rose, H., Vaughan, M., And Steinberg, D.: Utilization of fatty acids by rat liver slices as a function of medium concentration. Amer. J. Physiol., 206: 345 (1964).

17. Roux, J. F., TAKeda, Y., AND Gregorian, A.: Lipid concentra. tion and composition in human fctal tissue during development. Pediatrics, 48: 540 (1971).

18. Roux, J. F., AND Yoshioka, T.: Lipid metabolism in the fetus during development. Clin. Obst. and Gynec., 13: 595 (1970).

19. Roux, J. F., Yoshroka, T., ANd Myers, R. E.: Conversion of palmitate to respiratory carbon dioxide by fetal tissue of man and monkey. Nature, 227: 963 (1970).

20. Schonfeld, G.: Uptake and esterification of palmitate by rat diaphragm in vitro. J. Lipid Res., 9: $4: 53$ (1968).

21. SPERry, W. M.: Biochemistry of brain during early development. In: Neurochemistry, Ed. 2, p. 55. (Thomas Publishing Company, Springfield, Ill., 1962).

22. STAHL, E.: In: Thin-Iayer Chromatography, p. 147. (Academic Press, New York, 1965)

23. Szabo, A. J., Grimaldi, R. D., and Jung, W. F.: Palmitate transport across perfused human placenta. Metabolism, 18: 406 (1969).

24. Trout, D. L., Estes, E. H., JR., and Friedberg, S. J.: Titration of free fatty acids of plasma. A study of current methods and a new modification. J. Lipid Res., 1 : 199 (1960).

25. Van Duyne, C. M., Havel, R. J., and Felts, J. M.: Placental transfer of palmitic acid- $1{ }^{14} \mathrm{C}$ in rabbits. Amer. J. Obst. Gynec., 84: 1069 (1962).

26. Van Duyne, C. M., Parker, H. R., Havel, R. J., and Holm, L. W.: Free fatty acid metabolism in fetal and newborn sheep. Amer. J. Physiol., 199: 987 (1960).
27. Villee, C. A.: Metabolism of the placenta. Amer. J. Obst. Gynec., 84: 1684 (1962).

28. Villee, C. A., Hagerman, D. D., Holmberg, N., Lind, J., AND VILLEE, D. B.: The effect of anoxia on the metabolism of human fetal tissues. Pediatrics, 22: 953 (1958).

29. Armour Pharmaceutical Company, Chicago, Ill.

30. New England Nuclear Company, Boston, Mass.

31. Brinkman Instruments, Inc., Des Plaines, Ill.

32. Applied Science Laboratories, Inc., State College, Penna.

33. Packard Instrument Company, Inc., Downers Grove, Ill.

34. 274 and 275, Nuclear Chicago, Des Moines, Ill.

35. Model 852, Packard Instrument Company, Downers Grove, Ill.

36. Glucostat, Worthington Laboratories, Freehold, N.J.

37. The authors express their thanks to Mrs. Prabha Amin, Sister Mary Rose Mullin, H.M., and Mrs. Zenovia Perry, for their technical assistance.

38. Preliminary communications of this paper were published as abstracts of the Fifth Trophoblast Conference, Rochester, N.Y., 1969 and in Nature, 216: 819 (1967).

39. Dr. T. Yoshioka is a Lalor Fellow at Case Western Reserve University.

40. This research was supported by National Institute of Child Health and Human Development Grant no. 5 RO1-HD03261 and by Public Health Service Grant no. 5 MOI RR00210 (Perinatal Research Center Branch of General Clinical Research Centers, National Institutes of Health).

41. Requests for reprints should be addressed to: JAcQues $F$. Roux, M.D., Cleveland Metropolitan General Hospital, Cleveland, Ohio 44109 (USA).

42. Accepted for publication February 18, 1972. 